GEOMORPHOLOGY

\section{Plants hold back rivers}

Meandering rivers, which snake across landscapes around the world, often change shape and flow path, sculpting Earth's surface. River meanders are maintained when an equilibrium is reached between riverbed slope, the amount of flowing water and the mechanical strength of the substrate through which the river flows. Plants significantly and unquestionably affect river shape and migration by stabilizing river banks and helping to produce cohesive floodplain clays, thereby increasing resistance to erosion. However, evidence of meandering (as opposed to braided) rivers has been found in terrestrial deposits that pre-date land plants and ancient river forms on Mars, as well as in contemporary barren (unvegetated) landscapes on Earth. This has led to fierce debate of the necessity and role of vegetation in governing meandering river dynamics.

Alessandro Ielpi of Laurentian University, Canada, and Mathieu Lapôtre of Stanford University, USA, investigated vegetation impacts on active meandering rivers by compiling migration rates from 483 unvegetated rivers in arid regions and 500 heavily vegetated river meanders from cold, temperate, tropical and arid regions worldwide. In rivers of equal size, migration rates - derived

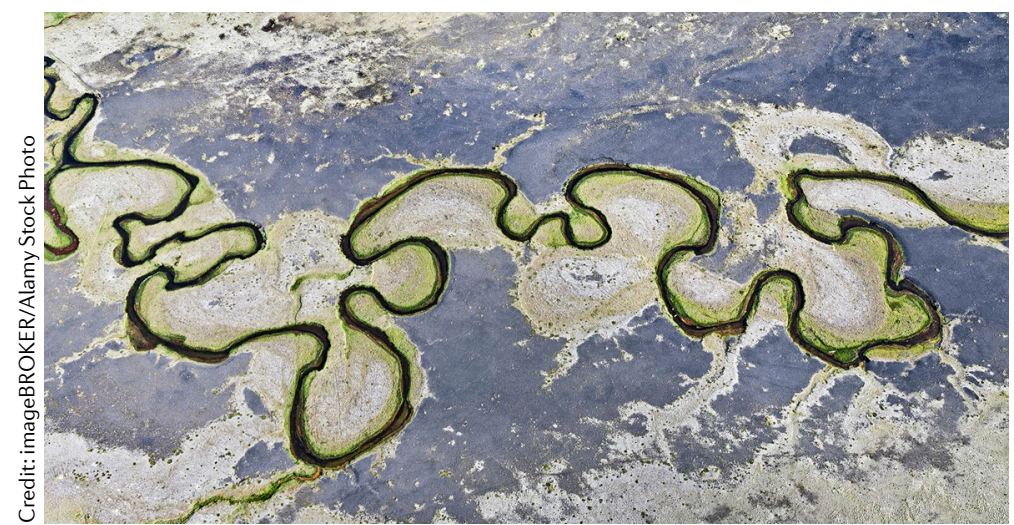

from time-lapse remote-sensing data - were substantially slower when vegetation was present, on average by tenfold. The slowdown in migration rate was not related to any other physical attribute of the river systems, including channel width, riverbed slope, catchment size or confinement within a valley, suggesting the presence of plants as a dominant control mechanism.

The rates and mechanisms influencing river migration provide new constraints for understanding broader biogeochemical cycling. In particular, reduced migration rates in meanders of vegetated systems indicate increased sediment residence times and therefore modulation of biogeochemical fluxes, including that of particulate organic carbon, for example. Moreover, the new migration rates can be used in investigations of landscape evolution in both Earth and planetary surfaces such as Mars. Although seemingly resolving the debate regarding vegetation's role in meander dynamics, future work is needed to better understand how vegetation (or lack thereof) interplays with other hydrologic and morphologic variables to control the rate of meandering.

Laura Zinke

ORIGINAL ARTICLE lelpi, A. N. \& Lapôtre, M. G. A.

A tenfold slowdown in river meander migration driven by plant life. Nature Geoscience https:// doi.org/10.1038/s41561-019-0491-7 (2019) 